\title{
STRUKTUR DIDONG ALO PADA MASYARAKAT \\ GAYO DI KECAMATAN BLANGKEJEREN \\ KABUPATEN GAYO LUES
}

\author{
PILAR KUNCORO AR \\ Prodi Pendidikan Tari
}

\begin{abstract}
This study discusses, Structure Didong A lo community in District Blangkejeren Gayo Gayo Lues District.
\end{abstract}

Theoretical foundation used in this study are: the theory of Levi-Strauss as seen from the outer structure and inner structure.

Data analysis techniques, used a qualitative description. The population in this study is the Gayo people in Desa Cempa Blangkejeren District of Gayo Lues district, Artist, dean or the Indigenous People, who know the neighbor Dancers dance tradition Gayo especially Didong A lo.

Based on the results of research conducted then, Didong A lo is a dance that tells the story of a white elephant sleeping in the area Gumpang. Didong A lo has a very unique shape on the movement of vague prop that movement would seize a bird chicks, sipped movement, and the movement kelileng accompanied by the chanting of poetry bebentuk vocals. A lo seen Didong structure based on the external structure and the structures within. The external structure into three parts, namely the implementation of the arrangement, visually and in audio. While the structure of the views of the whole contained within the outer structure. In the structure of the Didong A lo there are 3 stages: appetizer, contents and cover.

Keywords: Structural Didong A lo, the people of Gayo Lues 


\section{PENDAHULUAN}

Kabupaten Gayo Lues kaya akan tari-tarian kreasi yang mentradisi diantaranya Didong Jalu, Didong Niet, Didong A lo, Saman, Bines, dan Sening Bines. Tari Sening Bines adalah tari yang menceritakan tentang gajah putih yang tertidur di daerah Gumpang dan bermaksud berusaha untuk membangunkan serta mengusir gajah putih ke pusat ke Rajaan Aceh Darussalam yang dahulunya dinamakan Kute Reje. Pelaksanan tari ini dilakukan dari tempat yang satu ke tempat yang lain yang diawali dari Balai Sena (Kampung Penampaan), di lanjutkan ke Balai Gading dan pada akhirnya ke Balai Samsul di Kute Reje yang sekarang dinamakan Aceh Darussalam. Gajah Putih tertidur di daerah Gumpang atas kuasa Allah SWT. Masyarakat Gumpang sampai sekarang tidak tau dari sebabnya gajah putih itu bisa sampai ke Gumpang.

Berdasarkan cerita rakyat yang dikembangkan ditanah Gayo Lues, Didong Alo berawal dari mimpi seorang tokoh masyarakat yang dipercaya bernama. Dalam mimpi Syeh Abdul Saman melihat ada seseorang yang memberi amanah serta memberikan petunjuk, bagaimana cara membangunkan gajah putih untuk dibawa ke Balai Samsul di Kute Reje yaitu dengan mengadakan kesenian-kesenian salah satunya Didong $A$ lo. Dengan dimainkan kesenian tersebut, akhirnya dapat membangunkan dan membuat gajah putih dapat dituntun menuju ke Balai Samsul di Kute Reje.

Berdasarkan cerita ini kemudian masyarakat Gayo Lues melakukan Didong Alo. Tari ini dijadikan sebagai acara penyambutan disebuah kerajaan. Tarian ini dilakukan pertama kali dilakukan pada masa sebelum adanya penjajahan. Menurut sejarah, asal usul yang menciptakan Didong Alo berasal dari Arab antara lain:

- Seh Abdul Karim
- Seh Abdul Kadir Jailani

- Seh Abdul Saman

- Seh Nurdin

- Seh Ramli

- Seh Nurahim

- Seh Wahid

Didong A lo ditarikan oleh laki-laki (Sebujang) yang tidak di tentukan usianya baik dari kalangan anak-anak sampai kepada kalangan orang dewasa. Jummlah penari yaitu berjumlah 21 orang, 11 orang penari dari tuan rumah dan 10 orang penari dari tamu. Tarian ini sering digunakan untuk penyambutan para-para raja dan kaum bangsawan yang datang ke Gayo Lues. Seiring dengan transformasi kebudayaan dan zaman yang semangkin berkembang, Didong $A$ lo dahulunya hanya digunakan untuk menyambut para raja dan kaum bangsawan saat ini Didong $A$ lo semangkin mudah di jumpai di lingkungan masyarakat seperti di acara penyambutan sunatan (Ngeralik), bersaman (Besaman) dan ancara pernikahan pada masyarakat Gayo Lues, namun hal tersebut terdapat berbedaan makna dan prosedur masingmasing acara yang digunakan.

Didong A lo mempunyai bentuk yang sangat unik pada gerakan samar kalang yaitu gerakan seekor burung elang yang akan menyambar anak ayam, gerakan menyisip, dan gerakan kelileng serta menggunakan musik internal yaitu berupa syair lagu yang memiliki arti tertentu.

Didong Alo diamati dari gerak tangan, kaki, dan kepala. Didong Alo secara keseluruhan lebih menekankan gerakan pada bagian tangan dan kaki yang mempunyai ciri khas gerakan seekor burung elang menyambar anak ayam, dan menjadikan gerak ini serta mengandung nilai keindahan dalam tari Didong Alo. Selain keindahan dalam gerak, ada juga nilai-nilai dalam pakain busana yang dilihat dari warna, model, 
dan cara pemakaian, serta tetap mengikuti aturan-aturan ajaran Islam.

Dalam tari Didong Alo ini hubungan gerak, syair dan busana sangat disesuaikan dengan norma-norma adat dan aturan dalam ajaran Islam. Didong Alo adalah tari tradisi yang mempunyai arti Didong adalah tari, Alo adalah penyambutan Adapun bentuk penyajian Didong Alo secara berkelompok. Tari Didong Alo ditarikan oleh 3 sampai 11 penari Laki-laki, tidak ditentukan umur atau derajat penari tersebut. Dalam penyusunan gerak berdasarkan tahapan tersebut, terdapat hubungan antara satu kesatuan dalam tarian tersebut. Baik dari segi gerak, syair serta properti yang disebut dengan struktur. Dalam Didong Alo ini ialah bagaimana susunan dari satu tarian tersebut, serta adanya hubungan antara gerak dengan gerakan yang lain, hubungan antara gerak dan syair, properti dan busana.

Berdasarkan penjelasan latar belakang diatas, penulis merasa tertarik untuk mengangkat topik penelitian tentang Didong Alo. Hasil penelitian ini kiranya dapat menambah wawasan pembaca khususnya masyarakat suku Gayo serta dapat menjadi motivasi generasi muda suku Gayo untuk tetap menjaga, mempertahankan, melestarikan mewariskan budaya tersebut. Adapun judul penelitian ini adalah "Struktur Didong Alo Pada Masyarakat Gayo Di Kecamatan BlangkejerenKabupatenGayo Lues".

\section{LandasanTeori}

Untuk membahas Struktur Didong Alo pada Masyarakat Gayo, maka penulis menggunakan teori struktur yaitu struktur luar adalah relasi-realsi antar unsur yang dapat kita buat atau bangun, dalam hal ini Didong $A$ lo dilihat berdasarkan dari struktur luar dan sturktur dalam. Struktur luar menjadi tiga bagian yaitu susunan pelaksanaan, secara visual dan secara audio. Sedangkan struktur dalam dilihat dari keseluruhan yang tertuang didalam struktur luar. Pada struktur dalam Didong A lo ada 3 tahapan yaitu: pembuka, isi dan penutup.

\section{Lokasi dan Waktu Penelitian}

Sesuai dengan judul penelitian (Struktur Didong Alo pada masyarakat Gayo) maka, penelitian dilaksanakan pada masyarakat Gayo di desa Cempa Kecamatan Blangkejeren Kabupaten Gayo Lues. Waktu penelitian akan dilaksanakan pada bulan Januari 2016 sampai dengan bulan Maret 2016.

\section{Populasi dan Sampel}

Populasi dalam penelitian ini adalah Masyarakat Gayo di Desa Cempa Kecamatan Blangkejeren Kabupaten Gayo Lues yang mengetahui tentang Didong Alo , Seniman,Pengetua Adat atau Tokoh masyarakat yang mengetahui tentang Didong Alo, Penari yang mengetahui tetang tarian tradisi Gayo terutama Didong Alo.

Sampel dalam penelitian ini adalah Pengetua Adat atau Tokoh masyarakat yang mengetahui tentang Didong Alo, Penari Didong Alo, dan Didong Alo

\section{Teknik Pengumpulan Data}

Teknikpengumpulan data yang dilakukanadalahsebagaiberikut:

1. Studikepustakaan

2. Observasi

3. Wawancara

4. Dokumentasi

\section{TeknikAnalisis Data}

Dalampenelitianini data yang digunakan adalah analisis deskriptif kualitatif dimana penelitian ini sesuai dengan fakta sosial dan memberi gambaran, keterangan serta uraian.

\section{Gambaran Umum Masyarakat Gayo}

Dataran tinggi Gayo memiliki berbagai potensi yang dikembangkan 
masyarakat, ini tergantung pada tempat dan kondisinya, karena tidak semua lahan yang ada dataran tinggi Gayo dapat ditanam perkebunan kopi, sere wangi, padi ada beberapa sektor yang dipakai sebagai tempat untuk berternak seperti, kerbau, sapi, domba, biri-biri, dan kambing. Dalam selah-selah bertani dan berternak untuk mengisi kekosongan masyarakat Gayo melakukan keseniankesenian salah satunya Didong Alo dengan kesenian ini dapat menjadi penghibur dan melestarikan budaya agar tidak punah supaya berkembang terus di masyarakat.

\section{Struktur Didong Alo}

Telah disebukan sebelumnya, pemahaman tentang kajian struktur menyatakan bahwa struktur luar adalah relasi-realsi antar unsur yang dapat kita buat atau bangun, dalam hal ini menyatakan pada struktur Didong Alo, Struktur luar menjadi tiga bagian yaitu susunan pelaksanaan, secara visual dan secara audio. Sedangkan struktur dalam dilihat dari keseluruhan yang tertuang didalam struktur luar. Pada struktur dalam Didong $A$ lo ada 3 tahapan yaitu: pembuka, isi dan penutup.

\section{a. Tahapan Didong Alo dilihat dari struktur luar dan dalam.}

Tahapan yang dibicara kan dalam Didong Alo adalah proses yang dilakukan dalam penyajian dari awal sampai akhir proses penyajian ini dilihat dari struktur luar yaitu gerak dan syair, dan struktur dalam makna yang terkandung dari gerak dan syair. Hampir pada seluruh bagian Gerak Didong Alo memegang properti upuh kerawang (kain bermotif kerawang). Kedua ujung upuh kerawang dipegang tangan kiri dan tangan kanan yang menimbulkan efek seperti seekor burung elang yang sedang terbang di atas awan. Tahapan Didong Alo berdasarkan struktur dalam dibagi menjadi tiga yaitu:

1. Tahapan pembukaan:
Tari ini diawali dengan memberi salam pada orang tua dan para penonton yang menyaksikan Didong $A$ lo yang diungkapkan melalui syair agar diberi izin dapat melaksanakan Didong A lo . Dalam syair ini menggambarkan bahwa dalam melakukan setiap kegiatan selalu memberikan salam dan memohon ijin kepada Alam, orang tua, saudara, supaya segala kegiatan dapat dilakukan dengan lancar. Apabila dalam menarikan Didong A lo tidak sesuai dengan adat dan istiadat masyarakata gayo agar dapat dimaafkan.

2. Tahap Isi

Pada tahap isi Didong A lo tidak terlepas dari elemen -elemen tari yang dilihat secara visual dan Audio. Visual mencakup dalam gerakan, busana, waktu dan tempat, properti serta pelaku yang terlibat dalam pelaksanaan Didong A lo, sedangkan Audio menceritakan iringan musik Didong $A$ lo yang diamati dari gerak tangan, kaki, dan kepala. Didong $A$ lo secara keseluruhan lebih menekankan kepada gerakan pada kaki dan tangan yang mempunyai ciri khas diantaranya:

- Samar Kalang menggambarkan makna bahwa masyarakat Gayo memiliki sifat ramah tamah dan selalu terbuka dalam menjalin hubungan silaturahmi yang sudah diajarkan sesuai agama Islam dan dikembangkan dalam kehidupan sehari-hari.

- $\quad$ surang-saring (selang-seling) yaitu memiliki makna bahwasannya seluruh masyarakat Gayo diwajibkan saling tolong-menolong antara satu dengan lainnya dan selalu menegakkan keadilan sesuai dengan ajaran agama Islam yang terkandung dalam Al-Qur'an dan Hadist.

- berjalan melingkar (bepuseng) memiliki arti setiap umat beragama muslim diwajibkan apabila dia mampu menjalankan rukun Islam yang kelima, dimana rukun haji yaitu bertawaf mengelilingi Ka'bah 
yang bergerak melawan arah jarum jam.

- mengangguk-anggukkan kepala yaitu memiliki arti setiap seluruh masyarakat Gayo (jema opat) tanpa ketercuali wajib mengikuti, patuh dan tunduk apada ajaran agama Islam dan adat yang telah diberlakukan sejalan dengan UUD 1945.

Adapun ragam gerak pada Didong A lo yaitu ragam gerak pembuka yang hanya melakukan gerak membentuk sikap membentangkan upuh kerawang sejajar dengan sisi bahu kanan maupun kiri, ragam gerak berlari-lari kecil sambil membentangkan upuh kerawang yang masing-masing kedua ujungnya dipegang tangan kanan dan kiri dengan membentuk pola lantai seperti zig-zag (surangsaring), berjalan melingkar, mengangguk-anggukkan kepala, dari ragam-ragam tersebut ada yang dilakukan secara berulang-ulang dan disesuaikan dengan syair yang dinyayikan. Hampir seluruh bagian gerak Didong $A$ lo menggunakan properti upuh kerawang (kain bermotif kerawang). Kedua ujung upuh kerawang dipegang tangan kanan dan kiri yang menimbulkan efek seperti seekor burung elang yang sedang terbang bermain dan berjalan mencari makan dipinggir anak sungai.

Geh wekam beriringan naru bertamunen Harapni kami gere sengkeratu akal gera semelah (Kami mengharap sepenuhnya kepada para tamu agar sudi kiranya ikut merasakan kebahagiaan yang sama seperti pihak tuan rumah) maksud dari syair tersebut yang menggambarkan kebersamaan masyarakat dalam kebahagiaan dan kegembiraan kepada para tamu hal ini menggambarkan hubungan dalam mengikat persaudaraan. Dalam hal ini demikian juga penggunaan pola lantai dalam Didong A lo yang berbentuk lurus yang memiliki makna sistem kepercayaan pada masyarakat Gayo bahwa Tuhan itu hanya satu, yaitu Allah. Swt. Pola zik-zag menggambarkan topografi daerah dataran Gayo Lues yang berlembah-lembah, dan pola melingkar yang menggambarkan kebersamaan masyarakat Gayo yang menggambarkan kehidupan seperti roda berputar terkadang diatas dan dibawah, hendaknya setiap manusia haruslah tanamkan sifat ramah dan selalu menjalin hubungan kekeluargaan yang erat, tanpa adanya perbedaan.

\section{Tahap penutup}

Proses para penari menuju ke tempat acara yaitu dengan melakukan gerakan menari bersama dan salam-salaman kepada pihak tamu dan tuan rumah yang dilakukan dengan penuh semangat dan bahagia sambil mengayunkan tangan ke kanan dan ke kiri untuk mengiringi para tamu sampai di tempat acara. Sejalan dengan syair yang dinyanyikan seperti Salammualaikom-salammualaikom,

Jamut murum murum ganti nimat jari maksud dari syair di tersebut menggambarkan kepada seluruh masyarakat Gayo agar bertindak sesuai dengan aturan-aturan, adat-istiadat dan norma-norma di daerah agar perjalan kehidupan berjalan dengan baik. 
Uraian Gerak Didong A lo

\begin{tabular}{|c|c|c|c|c|c|c|}
\hline \multirow[t]{2}{*}{ No } & \multirow{2}{*}{$\begin{array}{l}\text { Ragam } \\
\text { Gerak }\end{array}$} & \multicolumn{4}{|c|}{ Cara melakukan } & \multirow[t]{2}{*}{ Gambar } \\
\hline & & Kepala & Torso & Tangan & Kaki & \\
\hline 1. & $\begin{array}{l}\text { Berlari- } \\
\text { lari } \\
\text { kecil }\end{array}$ & $\begin{array}{l}\text { Mengikut } \\
\mathrm{i} \text { arah } \\
\text { gerak } \\
\text { torso dan } \\
\text { tangan }\end{array}$ & $\begin{array}{l}\text { Torso } \\
\text { condong } \\
\text { ke depan } \\
\text { / Sedikit } \\
\text { membung } \\
\text { kuk }\end{array}$ & $\begin{array}{l}\text { Tangan } \\
\text { kanan } \\
\text { dan } \\
\text { tangan } \\
\text { kiri } \\
\text { memegan } \\
\mathrm{g} \text { sisi } \\
\text { ujung } \\
\text { upuh } \\
\text { kreawan } \\
g \quad \text { kain } \\
\text { kerawan) } \\
\text { yang di } \\
\text { letakkan } \\
\text { di } \\
\text { belakang } \\
\text { badan } \\
\text { penari } \\
\text { sejajar } \\
\text { dengan } \\
\text { kedua } \\
\text { bahu. }\end{array}$ & $\begin{array}{l}\text { Hitunga } \\
\mathrm{n} \quad 1-8 \\
\text { Kaki } \\
\text { kanan } \\
\text { dan kaki } \\
\text { kiri } \\
\text { melakuk } \\
\text { an lari- } \\
\text { lari kecil } \\
\text { lurus ke } \\
\text { depan } \\
\text { dengan } \\
\text { posisi } \\
\text { kaki } \\
\text { sedikit } \\
\text { di tekuk. }\end{array}$ & $\begin{array}{c}\text { (Dok.Pi } \\
\text { lar } \\
\text { Kuncor } \\
\text { o } \\
\text { AR: } 201 \\
6)\end{array}$ \\
\hline 2. & $\begin{array}{l}\text { Samar } \\
\text { Klang ( } \\
\text { gerakan } \\
\text { burung } \\
\text { elang } \\
\text { menya } \\
\text { mbar } \\
\text { mangsa } \\
\text { anak } \\
\text { ayam). }\end{array}$ & $\begin{array}{l}\text { Posisi } \\
\text { kepala } \\
\text { sedikit } \\
\text { menundu } \\
\mathrm{k} \text { dengan } \\
\text { penglihat } \\
\text { an fokus } \\
\text { kedepan } \\
\text { serta } \\
\text { mengikut } \\
\mathrm{i} \quad \text { arah } \\
\text { gerak } \\
\text { tangan } \\
\text { dan kaki }\end{array}$ & $\begin{array}{l}\text { Torso } \\
\text { condong } \\
\text { ke depan } \\
\text { l. Sedikit } \\
\text { membung } \\
\text { kuk dan } \\
\text { selalu } \\
\text { mengikuti } \\
\text { arah } \\
\text { gerakan } \\
\text { tangan } \\
\text { dan kaki. }\end{array}$ & $\begin{array}{l}\text { Setiap } \\
\text { hitungan } \\
1-3 \\
\text { tangan } \\
\text { kanan } \\
\text { diayunka } \\
\mathrm{n} \text { keatas } \\
\text { dengan } \\
\text { memegan } \\
\mathrm{g} \text { ujung } \\
\text { kerawang } \\
\text { gayo. } \\
\text { Pada } \\
\text { hitungan } \\
\text { 4-5 } \\
\text { tangan } \\
\text { kanan } \\
\text { turun dan } \\
\text { pada saat } \\
\text { hitungan } \\
\text { 4-6 } \\
\text { tangan } \\
\text { kiri juga } \\
\text { mengikut } \\
\mathrm{i} \quad \text { juga } \\
\text { gerakan } \\
\text { yang } \\
\text { sama } \\
\text { dilakuka } \\
\mathrm{n} \quad \text { oleh } \\
\text { tangan } \\
\text { kanan. } \\
\text { Seolah- } \\
\text { olah } \\
\text { gerakan } \\
\text { terbang } \\
\text { bebas di } \\
\text { udara. } \\
\text { Begitu } \\
\text { juga hal } \\
\text { yang } \\
\text { sama } \\
\text { dilakuka } \\
\mathrm{n} \text { dengan } \\
\text { para } \\
\text { kelompo } \\
\mathrm{k} \text { tamu } \\
\text { dengan } \\
\text { arah } \\
\text { hadap } \\
\text { yang } \\
\text { berlawan } \\
\text { an. }\end{array}$ & $\begin{array}{l}\text { Pada } \\
\text { hitungan } \\
1 \text {-2 kaki } \\
\text { kanan } \\
\text { dan kaki } \\
\text { kiri } \\
\text { berlari- } \\
\text { lari kecil } \\
\text { dengan } \\
\text { arah ke } \\
\text { kiri dan } \\
\text { pada } \\
\text { hitungan } \\
\text { 3-4 } \\
\text { berubah } \\
\text { arah } \\
\text { hadap ke } \\
\text { arah } \\
\text { kanan, } \\
\text { dan } \\
\text { begitu } \\
\text { seterusn } \\
\text { ya, sama } \\
\text { hal yang } \\
\text { dilakuka } \\
\text { n dengan } \\
\text { para } \\
\text { penari } \\
\text { tamu } \\
\text { melakuk } \\
\text { an } \\
\text { gerakan } \\
\text { seperti } \\
\text { ini, } \\
\text { hanya } \\
\text { saja arah } \\
\text { hadap } \\
\text { pernari } \\
\text { tamu } \\
\text { dan tuan } \\
\text { rumah } \\
\text { yang } \\
\text { berlawa } \\
\text { nan. }\end{array}$ & $\begin{array}{l}\text { } \\
\text { (Dok.Pi } \\
\text { lar } \\
\text { Kuncor } \\
\text { o } \\
\text { AR:201 } \\
\text { 6) }\end{array}$ \\
\hline
\end{tabular}

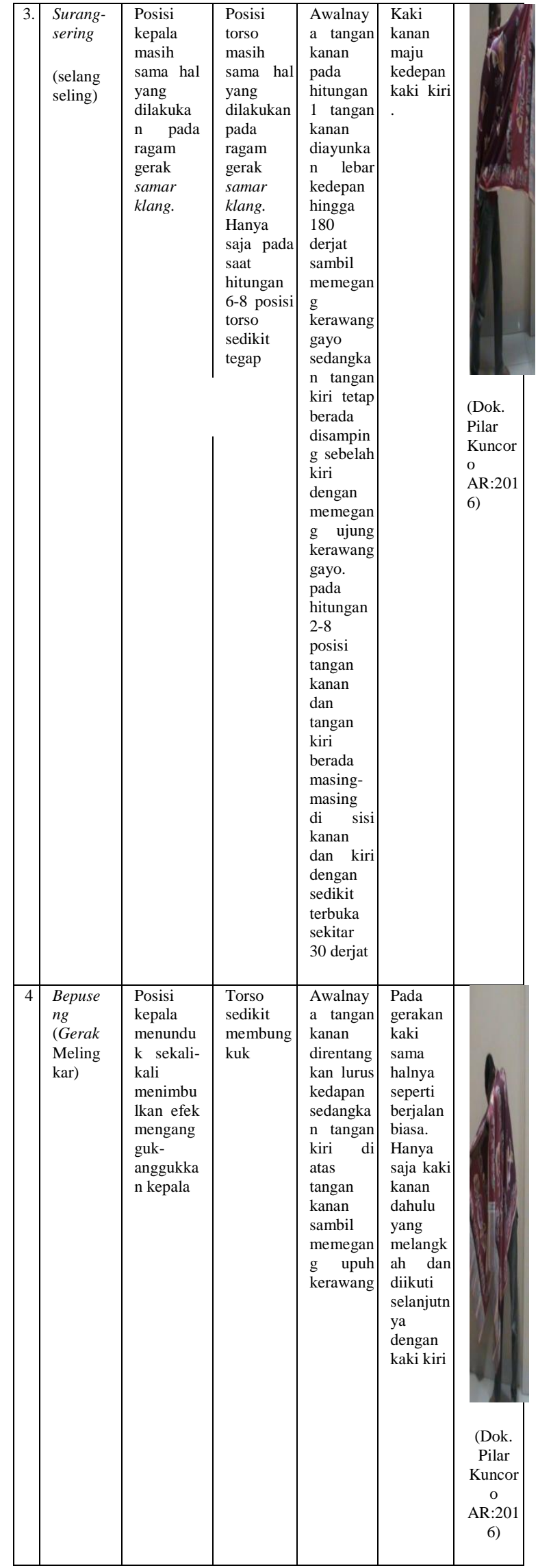


PENUTUP

\section{Kesimpulan}

Dari hasil penelitian yang dilakukan di lapangan dan penejelasan yang sudah di uraikan mulai dari latar belakang hingga pembahasan, maka dapat disimpulkan secara keseluruhan terhadap Didong A lo pada masyarakat Gayo di Kecamatan Blangkejeren Kabupaten Gayo Lues sebagai berikut:

1. Didong A lo terinspirasi dari mimpi seorang syeh yang bernama syeh Abdul Saman melihat dua sekumpulan Burung Elang yang sedang terbang diatas awan datang dari arah lawanan, dimana para burung saling bergerak bertemu di satu titik temu dan para burung saling bermain yang kemudian membuat pola lantai berbentuk lingkaran di atas awan dengan satu tujuan yaitu ingin memangsa buruan yang ingin ditangkap secara bersamaan oleh burung-burung elang dan memakan hasil tangkapannya secara bersama-sama. Hal ini membuat Seh Abdul Saman diberikan sebuah petunjuk kepada seseorang yang memberikan amanah serta memberikan petunjuk baginya, bagaimana cara membangunkan dan mengusir dengan tujuan Gajah Putih bisa dibawa ke Balai Samsul di Kute Reje yaitu dengan mengadakan kesenian Didong A lo..

2. Didong A lo secara keseluruhan lebih menekankan gerakan pada bagian kaki yang mempunyai ciri khas geraksamar kalang, dan menjadikan gerak ini serta mengandung nilai keindahan dalam Didong A lo. Selain keindahan dalam gerak, ada juga nilai-nilai dalam pakain busana yang dilihat dari warna, model, dan cara pemakaian, serta tetap mengikuti aturan-aturan ajaran Islam.

3. Pada Didong A lo terdapat tiga tahap penyajian yaitu antara lain Pembukaan, isi dan pentup. Tahapan tersebut termasuk kedalam struktur tarian tersebut. Selain itu, pada pebahasan struktur juga terdapat hubungan antara satu kesatuan pada Didong $A$ lo tersebut yaitu antara Didong $A$ lo dengan busana serta syair yang dilantunkan.

Dari hasil kesimpulan penelitian diatas, maka dapat diajikan beberpa saran antara lain sebagai berikut :

1. Penulis berharap dengan adanya peneltian ini masyarakat Gayo untuk menjaga , mengembangkan serta melestarikan tari-tarian yang berada pada masyarakat Gayo khususnya di Kabupaten Gayo Lues.

2. Diharapkan kepada masyarakat Gayo khususnya kepada pemerintah daerah agar senantiasa memperkenalkan berbagai tari-tarian kepada masyarakat luas baik lokal maupun diluar daerah. Dengan begitu keberadaan tari-tarian tersbut.

3. Dengan meningkatkan kepedulian terhadap kesenian daerah, berarti telah menyelamatkan anak cucu kita dari pengaruh budaya luar yang akan merusak budaya sendiri.

4. Semoga penelitian ini dapat memberikan pengetahuan baru bagi masyarakat lues bagaimana sruktur Didong Alo. 


\section{DAFTAR PUSTAKA}

Agustina, Milana (2012). Kesenian Didong Alo da Didong Tepok Pada Acara Pesta Perkawinan Jeuelen di Gayo Lues. Skripsi Universitas Negeri Medan.

Darsono (2007). Kebudayaan

Nusantara. Jakarta : PT Raja Grafindo Persada.

Desiana Syahzuar, Wahyu. (2014). Tari Kesume Gayo Pada Masyarakat Kabupaten Aeh Tengah Tinjauan Terhadap Bentuk. Skripsi Universitas Negeri Medan.

Ernawati 2013. Eksplanasi Tari Ddong A

lo Pada Masyarakat Gayo Lues.Skripsi Universitas Negeri Medan.

Ahimsa Putra Heddy Shri (2001).

Strukturalisme Levi-Strauss

Mitos dan Karya Sastra.

Dalman, H. (2012). Menulis Karya Ilmiah. Jakarta: PT RajaGrafindo Persada.

Endraswara, Suwardi. (2006). Metode, Teori, Teknik Penelitian Kebudayaan. Sleman: Pustaka Widyatama.

Ihromi (2000). Pokok Antropologi Budaya. Jakarta: Gramedia.

Royce, Anya Peterson. (2007). The Antthropology of Dance. (F.X Widaryanto.Terjemahan). First Midland. Buku asli diterbitkan Tahun 1980

Soedarsono.(1972). Djawa Bali: Dua Pusat Perkembangan Dramaturgi Tradisionel di Indonesia. Yogyakarta: Gadjah Mada Universitas Press.
Soeharto, Ben (1985), Komposisi Tari. Yogyakarta: Ikalasti Yogyakarta.

Soekanto, Soerjono. (1990). Sosiologi, Suatu Pengantar. Jakarta: PT. Raja Grafindo Persada.

Sugiyono. (2010). Metode Penelitian Kuantitatif Kualitatif dan $R \& D$. Bandung: Alfabeta.

Syai, Ahmad (2012). Bines Tradisi Berkesenian Masyarakat Dataran Tinggi Gayo. Balai pelestarian Nilai Budaya Banda Aceh

Tantawi Isma, Buniyamin. (2011). Pilarpilar Kebudayaan Gayo Lues. Medan: Usu press

T. Syamsudun dkk, (1979/1980). Sistem Gotong Royong dalam Masyarakat Pedesan Provinsi Daerah Istimewa Aceh. Aceh: Departemen Pendidikan dan Kebudayaan.

Wahyu Desiana Syahzuar (2014) "Tari Kesume Gayo Pada Masyarakat Gayo Kabupaten Aceh Tengah Tinjauan Terhadap Bentuk". Skripsi Universitas Negeri Medan.

Nurwani. (2007). Pengetahuan Tari. Diktat. Universitas Negeri Medan. Semandari 2015. Struktur Sening Bines Pada Masyarakat Gayo di Kabupaten Gayo Lues. Skripsi Universita Negeri Medan. 